\title{
Bioavailability of vitamin $\mathrm{D}_{2}$ from irradiated mushrooms: an in vivo study
}

\author{
Viraj J. Jasinghe*, Conrad O. Perera and Philip J. Barlow \\ Department of Chemistry, Food Science \& Technology Programme, National University of Singapore, 3 Science Drive 3 , \\ Singapore 117543 \\ (Received 28 September 2004 - Revised 13 December 2004 - Accepted 5 January 2005)
}

\begin{abstract}
Vitamin $\mathrm{D}_{2}$ from irradiated edible mushrooms might present a possible dietary source of this vitamin, subject to its bioavailability. Having previously optimized a method for the conversion of ergosterol in mushrooms to vitamin $\mathrm{D}_{2}$, this paper examines the vitamin $\mathrm{D}$-enriched mushrooms (Lentinula edodes) for their bioavailability of the vitamin, using an animal model. Thirty male Wistar rats were fed for 1 week with a diet deficient in vitamin D. After this 1 -week period, six rats were randomly selected and killed for analysis of initial bone mineral density, and serum level of 25-hydroxyvitamin D. A group of twelve rats of the test animals received $1 \mu \mathrm{g}$ of vitamin $\mathrm{D}_{2}$ from irradiated mushrooms for a period of 4 weeks until being killed. The remaining twelve rats were fed un-irradiated mushrooms at the same level to act as controls. At the end of a 4-week period, the mean serum 25-hydroxyvitamin D level of the experimental group was 129.42 (SD 22.00) nmol/l whereas it was only 6.06 (SD 1.09) nmol/l in the control group. Femur bone mineral density of the experimental group of animals was significantly higher $(P<0 \cdot 01)$ than the control group. In addition, serum Ca concentrations among groups were shown to be significantly higher $(P<0 \cdot 01)$. It may be concluded from the results that vitamin $\mathrm{D}_{2}$ from UV-irradiated mushrooms is well absorbed and metabolized in this model animal system. Significant increase in femur bone mineralization $(P<0 \cdot 01)$ was shown in the presence of vitamin $\mathrm{D}_{2}$ from irradiated mushrooms compared with the controls.
\end{abstract}

Vitamin $\mathrm{D}_{2}$ : Ergosterol: Shiitake mushrooms: Bioavailability

In 1919, vitamin D, sometimes referred to as the 'sunshine vitamin' was discovered by Sir Edward Mellanby (Mellanby, 1919) as part of his experiments on rickets. The main role of vitamin $\mathrm{D}$ in the body is functioning as a hormone in maintaining $\mathrm{Ca}$ homeostasis, important in the mobilization, retention, and bone deposition of $\mathrm{Ca}$ and $\mathrm{P}$. Clinically, vitamin $\mathrm{D}$ deficiency has been shown to be associated with cancers (Sadava et al. 1996; Platz et al. 2000; Burton, 2001; Hansen et al. 2001; Grant, 2002; Mehta \& Mehta, 2002; Polek \& Weigel, 2002), heart diseases (Williams \& Lloyd, 1989; Mancini et al. 1996; Norman et al. 2002; Zittermann et al. 2003), obesity (Heldenberg et al. 1992; Cantorna, 2000; Speer et al. 2001), diabetes (Billaudel et al. 1998; Bourlon et al. 1999; Hypponen et al. 2001), and arthritis (McAlindon \& Felson, 1996; Braun \& Tucker, 1997). In addition, Vitamin D has been suggested for therapeutic applications in the treatment of several diseases including hyperproliferative diseases, secondary hyperparathyroidism, post-transplant survival, and various malignancies (Peleg, 1997).

Vitamin D deficiency disorders are common all over the world (Diamond et al. 2000; Ravinder et al. 2000; Semba et al. 2000; Yan et al. 2000; Vieth et al. 2001). Vitamin D deficiency is an unrecognized epidemic among the elderly population and more than $50 \%$ of elderly persons, living in their own homes and nursing homes in the USA, are reported as deficient in vitamin D (Holick, 2001). Hence, the introduction of an alternative dietary source of vitamin D would most likely be helpful in protecting this population from such a deficiency.
Naturally, wild mushrooms contain only small amounts of vitamin $\mathrm{D}_{2}$ but are abundant in ergosterol (Mau et al. 1998; Mattila et al. 2002). Mushrooms are considered a delicacy, highly accepted by vegetarians as well as non-vegetarians, and could be used to supplement vitamin $\mathrm{D}_{2}$ content in the diets of those populations at risk of vitamin $\mathrm{D}$ deficiency.

In a previous study (Perera et al. 2003; Jasinghe \& Perera, 2005), it was shown that UV-B irradiation of cultivated mushrooms gave rise to remarkable amounts of vitamin $\mathrm{D}_{2}$. However, use of this information in introducing cultivated mushrooms as an alternative to vitamin D supplement must be subject to the investigation of bioavailability of vitamin $\mathrm{D}_{2}$ from the irradiated mushrooms.

There are few studies on the bioavailability of vitamin D. However, most of the studies have been carried out using supplements. The absorption of vitamin D from supplements in humans is estimated at about $55-99 \%$ and the values from food sources are probably lower (Van-den-Berg, 1997). The biologically active metabolite of vitamin $\mathrm{D}_{2}$ is 25 -hydroxyvitamin $\mathrm{D}_{2}$ (Suda et al. 1969), and measurement of this compound is considered to be the best indicator of vitamin D status (Holick et al. 1986). Furthermore, 25-hydroxyvitamin D, which is the major circulating form of vitamin $\mathrm{D}$, is more suitable as an index of vitamin D status than 1,25-dihydroxyvitamin D, since the half-life of 25-hydroxyvitamin $\mathrm{D}$ is more than $7 \mathrm{~d}$ and it is circulated in the body at a concentration some 1000 times more than 1,25-dihydroxyvitamin D (Holick, 2004). Therefore, serum levels of 
25-hydroxyvitamin D may be used as a sensitive indicator in the investigation of bioavailability of vitamin $\mathrm{D}_{2}$ in in vivo studies. In addition, vitamin $\mathrm{D}$ deficiency is also associated with bone loss and incidence of fractures (Parfitt et al. 1982; Lips \& Obrant 1991; Dawson-Hughes et al. 1995) and therefore measurement of bone mineral density (BMD) could also be used to evaluate vitamin D deficiency status.

Except for one human bioassay (Outila et al. 1999), there appears to be no reported data on bioavailability of vitamin $\mathrm{D}_{2}$ from natural food sources. Hence the focus of this study was to investigate the bioavailability of vitamin $\mathrm{D}_{2}$ from irradiated edible mushrooms in order to understand its biological activity and the possibility of using this food source to help in eradication of vitamin D deficiency from affected or at-risk populations.

\section{Materials and methods}

\section{Animal model}

All the procedures were performed according to an approved project protocol, which complied with the Singapore Agri-Food and Veterinary Authority (AVA) regulations, and abided with National Advisory Committee for Laboratory Animal Research (NACLAR), by the laboratory animal centre of the National University of Singapore.

Thirty male Wistar rats (average weight $54 \cdot 32 \pm 5.12 \mathrm{~g}$ ) were obtained from the laboratory animal-breeding centre, National University of Singapore. All the rats were housed in individual plastic cages at $25^{\circ} \mathrm{C}$ under incandescent lighting. Initially, all the rats were given a diet deficient in vitamin D with $0.47 \% \mathrm{Ca}$ and $0.3 \%$ P (Diet TD89123, Teklad Premier Laboratory Diets, Madison, WI, USA) in order to induce vitamin D deficiency. After 1 week, six rats were randomly selected (Group 1), and killed to analyse initial BMD and serum levels of 25-hydroxyvitamin D. A group of twelve rats (Group 2) were administered a known amount $(28 \mathrm{mg})$ of lyophilized, powdered, irradiated Shiitake mushrooms, containing $1 \mu \mathrm{g}$ vitamin $\mathrm{D}_{2} / \mathrm{d}$, while the control group (Group 3) received the same amount of non-irradiated Shiitake mushrooms, confirmed to be absent of vitamin $\mathrm{D}_{2}$. During the irradiation, each side (caps and gills) of the Shiitake mushrooms was irradiated with UV-B (UV-B Model UVM-57; UVP Inc., Upland, CA, USA) for $1 \mathrm{~h}$. Mushrooms were placed in an irradiation chamber at a distance $15 \mathrm{~cm}$ away from the source of UV-B while irradiation was performed at ambient temperature $\left(27^{\circ} \mathrm{C}\right)$. The calculated irradiation dose after a $2 \mathrm{~h}$ period of irradiation ( $1 \mathrm{~h}$ each side) was $35.3 \mathrm{~kJ} / \mathrm{m}^{2}$. The test diets $(28 \mathrm{mg}$ freeze-dried, irradiated and non-irradiated mushroom powder) were administered in liquid form (suspended in $0.5 \mathrm{ml}$ deionized water) directly into their stomachs through a gavage tube, while both groups were given free access to deionized water and the vitamin D-deficient diet. The daily dietary intake and the weight gain were measured using an electronic analytical balance, and at the end of the 4-week period, all the rats were killed for analysis of femur BMD and level of serum 25-hydroxyvitamin D.

\section{Measurements of 25-hydroxyvitamin $D_{2}$, serum calcium and bone mineral density}

Serum 25-hydroxyvitamin D was analysed at the Singapore National University Hospital using a Gamma-B 25-hydroxyvitamin D ${ }^{125}$ I RIA kit (DiaSorin and IDS Ltd, Boldon, UK) as directed by the manufacturer's product guidelines. This RIA method does not discriminate between 25-hydroxyvitamin $\mathrm{D}_{2}$ and 25-hydroxyvitamin $D_{3}$. Serum 25-hydroxyvitamin D-bound radioactivity was measured by a gamma well-counting system (Berthold DPC Gamma-C12 multi crystal gamma counter, Berthold, Wilberg, Germany). Serum Ca levels were measured at the Singapore National University Hospital using an automated VITROS 950 chemistry system (Ortho-Clinical Diagnostics, Inc., Raritan, NJ, USA). The BMD of femur bones and the lengths of femur bones were measured at the Singapore National University Hospital with a Lunar DPX-L Dual-Energy X-ray Bone Densitometer, software version 1.3 (Lunar DPX-L, Lunar Corp., Madison, WI, USA).

\section{Statistical analysis}

The evaluation of equality of means was carried out by the oneway ANOVA using the $F$ distribution to assess significance (VassarStats, http://vassun.vassar.edu/ lowry/VassarStats.html). The data are expressed as means with their standard deviations.

\section{Results}

All the subjects survived until they were killed at the end of the study and neither physiological nor behavioural abnormalities were observed in any group. The ranges of measurements are tabulated in Table 1.

The body weights at the beginning and end of the study did not differ among groups $(P<0 \cdot 01)$. Furthermore, the lengths of femur bones did not differ among groups. No significant difference $(P<0.01)$ was shown in daily dietary intakes of Groups 2 and 3. Group 1 was used to evaluate the vitamin D deficiency status

Table 1. Basic measurements of group physical parameters (Values are means with their stantard deviations)

\begin{tabular}{|c|c|c|c|c|c|c|}
\hline \multirow{2}{*}{ Measurement } & \multicolumn{2}{|c|}{ Group 1* } & \multicolumn{2}{|c|}{ Group $2 \dagger$} & \multicolumn{2}{|c|}{ Group 3‡ } \\
\hline & Mean & SD & Mean & SD & Mean & SD \\
\hline Body weight at commencement of the experiment $(\mathrm{g})$ & $54 \cdot 32$ & $5 \cdot 12$ & $99 \cdot 24$ & 4.64 & 93.92 & $7 \cdot 68$ \\
\hline Body weight when killed $(\mathrm{g})$ & $89 \cdot 40$ & 4.63 & 311.87 & 23.36 & 294.55 & $19 \cdot 06$ \\
\hline Dietary intake $(\mathrm{gd})$ & $10 \cdot 56$ & 2.51 & $22 \cdot 78$ & 3.42 & $22 \cdot 35$ & 3.14 \\
\hline Length of right femur (mm) & $18 \cdot 89$ & $1 \cdot 15$ & $20 \cdot 68$ & 1.96 & $20 \cdot 86$ & 2.05 \\
\hline Length of left femur (mm) & $18 \cdot 70$ & 1.23 & $19 \cdot 87$ & 3.56 & $20 \cdot 11$ & 1.33 \\
\hline
\end{tabular}

*Group 1 on vitamin D-deficient diet for 1 week. Measurements after 1 week, $n 6$.

† Group 2 on vitamin D-deficient diet for 1 week and then irradiated mushrooms + vitamin D-deficient diet for 4 weeks. Measurements after 5 weeks, $n 12$.

‡Group 3 on vitamin D-deficient diet for 1 week, and then non-irradiated mushrooms + vitamin D-deficient diet for 4 weeks. Measurements after 5 weeks, $n 12$. 
of animals before the administration of test diets. Figure 1 illustrates femur BMD of the three different groups.

Femur BMD of Group 2 was significantly higher $(P<0 \cdot 01)$ than that of the other two groups. The difference in BMD between Group 1 and Group 3 was shown to be not significant $(P=0 \cdot 332)$. In addition, the BMD values of right and left femurs within the groups were similar and the difference between values was shown not to be significant (Group 1, $P=1.00$; Group 2, $P=0 \cdot 434$; Group 3; $P=0 \cdot 487$ ). Serum 25-hydroxyvitamin D and Ca concentrations of the groups are shown in Table 2.

The results show that serum 25-hydroxyvitamin D concentration of Group 2 clearly differs from that of Groups 1 and 3 . The serum 25-hydroxyvitamin D concentration of Group 2, which received $1 \mu \mathrm{g}$ vitamin $\mathrm{D}_{2}$ daily from mushrooms for 4 weeks, was 129.42 (SD 22.00) nmol/l whereas it was only 6.06 (SD 1.09) nmol/1 in Group 3, which received no vitamin $\mathrm{D}_{2}$. A decrease in 25-hydroxyvitamin $\mathrm{D}$ concentration was observed in Group 3 compared with Group 1 but, on the other hand, a remarkable increase was observed in Group 2. The serum Ca levels among groups were also significantly different. In contrast to what might have been expected, the serum Ca level of Group 2 was significantly lower compared with Group 1 . This could be due to a higher rate of bone mineralization in Group 2 (which received vitamin $\mathrm{D}_{2}$ from mushrooms) compared with Group 1. This is supported by the observation that there was a significantly higher BMD and lengths of femur bones in Group 2. In addition, lowered serum levels of parathyroid hormone, raised serum ionized $\mathrm{Ca}$ levels and an age-related decline in duodenal $\mathrm{Ca}$ absorption have all been reported, and could be contributing factors to this difference (Liang et al. 1989; Takamoto et al. 1990; Agnusdei et al. 1998; Schulz \& Morris, 1999).

\section{Discussion}

Bioavailability has been defined as 'that fraction of an oral dose (parent compound or active metabolite) from a particular preparation that reaches the systemic circulation' (Schumann et al. 1997). The serum concentration of 25-hydroxyvitamin $\mathrm{D}$ is the barometer of vitamin D status (Holick, 2001), and therefore this measurement can be used in bioavailability studies of vitamin $\mathrm{D}$.

In this study, the difference in daily dietary intake of Groups 2 and 3 was shown to be not significant $(P=0.853)$. Assuming only vitamin $\mathrm{D}_{2}$ was formed in mushrooms under UV radiation, Group 2 received $1 \mu \mathrm{g}$ of vitamin $\mathrm{D}_{2}$ from irradiated mushrooms while Group 3 received a similar diet but lacking the vitamin $\mathrm{D}_{2}$. Since the animals were housed under incandescent light, cutaneous synthesis of vitamin D was not expected to interfere with the results.

The current results clearly indicate that vitamin $\mathrm{D}_{2}$ from irradiated mushrooms was well absorbed in the laboratory rats since the serum concentration of 25-hydroxyvitamin D of the experimental group was remarkably higher than the control group. Vieth \& Milojevic (1995) reported a value of 58 (SD 8) $\mathrm{nmol} / 1$ 25-hydroxyvitamin $\mathrm{D}$ in a similar rat study using vitamin $\mathrm{D}_{3}$ as a supplement. In this study, the quantities of vitamin $\mathrm{D}$ administered were considerably higher than the amount of vitamin $\mathrm{D}$ given there, and this may be the reason for the observation of high values of serum 25-hydroxyvitamin D in this study. The results of this study show dramatic increases in serum 25-hydroxyvitamin $\mathrm{D}$ in rats fed with vitamin $\mathrm{D}_{2}$ from irradiated mushrooms compared with the values reported by Outila et al. (1999) in a human study.

Since vitamin D influences several steps in the active Ca transport system (Bronner, 1987, 1992; Gueguen \& Pointillart, 2000), measurement of serum $\mathrm{Ca}$ concentration is a useful tool to predict vitamin D deficiency. Serum Ca concentration of Group 2 was significantly higher than that of the value for Group 3. Thus, it was clearly indicated that Group 3, fed only on vitamin Ddeficient diet, was indeed deficient in vitamin $\mathrm{D}$.

The dual-energy X-ray bone densitometer is a useful tool for measuring intact and excised rat leg BM (Nagy et al. 2001). In this study, it was shown that vitamin $\mathrm{D}_{2}$ from irradiated mushrooms increased femur BMD of laboratory rats. Since vitamin

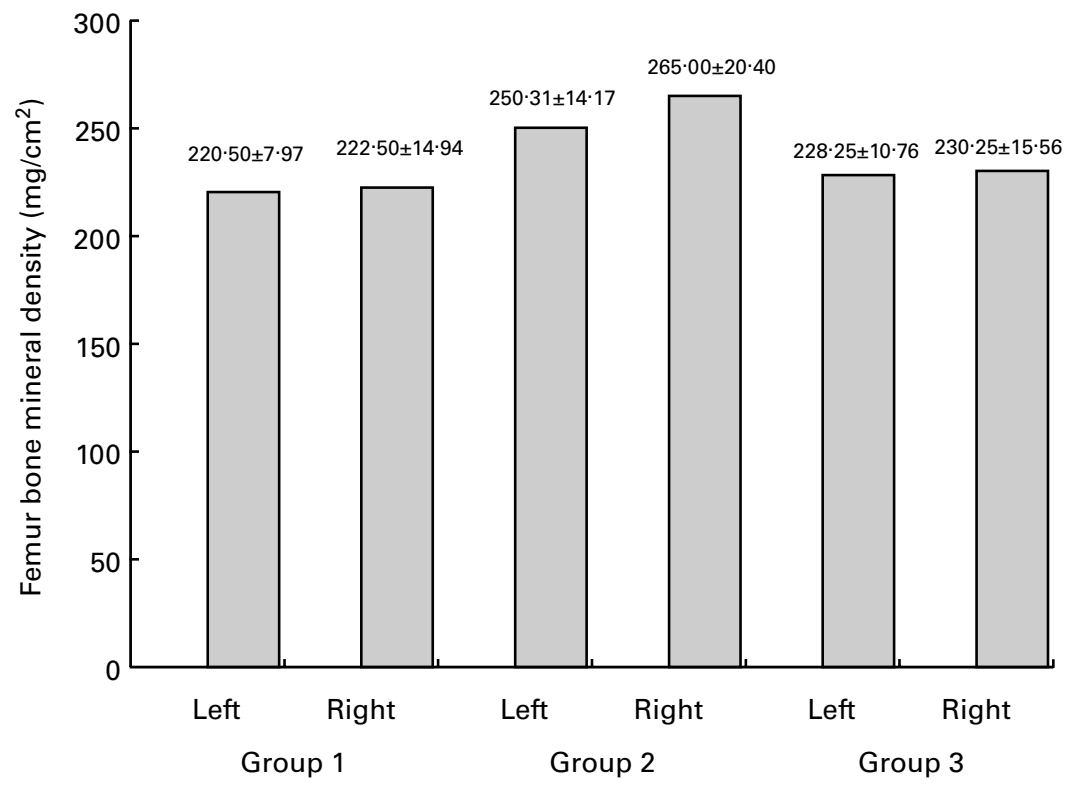

Fig. 1. Femur (left and right) bone mineral density of initial (Group 1), experimental (Group 2) and control (Group 3) groups. Values are means with their standard deviations. 
Table 2. Serum 25-hydroxyvitamin D and serum ca concentrations of groups* (Values are means with their stantard deviations)

\begin{tabular}{|c|c|c|c|c|c|c|}
\hline \multirow[b]{2}{*}{ Variable } & \multicolumn{2}{|c|}{ Group 1} & \multicolumn{2}{|c|}{ Group 2} & \multicolumn{2}{|c|}{ Group 3} \\
\hline & Mean & SD & Mean & SD & Mean & SD \\
\hline Serum 25-hydroxyvitamin D (nmol/l) & $18 \cdot 06^{\mathrm{a}}$ & $5 \cdot 26$ & $129 \cdot 42^{b}$ & $22 \cdot 0$ & $6 \cdot 06^{\mathrm{c}}$ & 1.09 \\
\hline Serum ca (mmol/l) & $2 \cdot 61^{a}$ & 0.32 & $2 \cdot 28^{\mathrm{b}}$ & 0.11 & $1 \cdot 60^{\mathrm{C}}$ & 0.24 \\
\hline
\end{tabular}

D is directly involved in bone mineralization (Schapira et al. 1995; Erben et al. 1997, 1998, 2002; Kaastad et al. 2001), the results of the current study show that in laboratory rats, vitamin $\mathrm{D}_{2}$ from irradiated edible mushrooms has an important positive effect on the femur bone mineralization, especially during the period that the rats lay down their skeleton. In conclusion, vitamin $\mathrm{D}_{2}$ from irradiated edible mushrooms is well absorbed, metabolized to 25-hydroxyvitamin $\mathrm{D}_{2}$, and possesses an active role in bone mineralization in animals. The dose of vitamin $\mathrm{D}_{2}$ for rats, which was used in this study, was about $3 \mu \mathrm{g} / \mathrm{kg}$ body weight. If this dose is converted to an average body weight of a human $(70 \mathrm{~kg})$, it is about $200 \mu \mathrm{g} / \mathrm{d}$. This is approximatly 20 times higher compared with the current RDA of vitamin D for adults $(10 \mu \mathrm{g} / \mathrm{d})$, which some workers believe to be inadequate (Hanly et al. 1985; McKenna et al. 1985, 1995; Chapuy et al. 1997; McKenna \& Freaney, 1998; Compston, 1998; Cheetham, 1999; Vieth, 1999, 2000; Heaney, 2000), and even up to $100 \mu \mathrm{g}$ vitamin $\mathrm{D}_{3} / \mathrm{d}$ is a safe intake (Vieth et al. 2001). Irradiated edible mushroom powder could be used in the fortification of human food supplements or fresh irradiated mushrooms could be used for human consumption. However, the optimal therapeutic dosage of vitamin, and the effect of its administration on the other animal organs, especially the liver, heart and kidney, hypercalcaemic effect, and the systemic metabolism to its active analogues, have yet to be elucidated.

\section{Acknowledgements}

This research was supported by an academic research grant from the National University of Singapore (R-143-000-138-112). The authors wish to thank Ms Low Siew Leng for her kind assistance with the BMD analysis; and Dr Enoka Bandularatne, Dr Retnam Leslie and the animal house staff for maintaining the animals and providing valuable assistance in handling of the animals.

\section{References}

Agnusdei D, Civitelli R, Camporeale A, Parisi G, Gennari L, Nardi P \& Gennari C (1998) Age-related decline of bone mass and intestinal calcium absorption in normal males. Calcif Tissue Int 63, 197-201.

Billaudel B, Barakat L \& Faure-Dussert A (1998) Vitamin $D_{3}$ deficiency and alterations of glucose metabolism in rat endocrine pancreas. Diabetes Metab 24, 344-350.

Bourlon PM, Billaudel B \& Faure-Dussert A (1999) Influence of vitamin $\mathrm{D}_{3}$ deficiency and 1,25 dihydroxyvitamin $\mathrm{D}_{3}$ on de novo insulin biosynthesis in the islets of the rat endocrine pancreas. Endocrinology 160, $87-95$.

Braun MM \& Tucker MA (1997) A role for photoproducts of vitamin D in the etiology of cutaneous melanoma? Med Hypotheses 48, 351-354.
Bronner F (1987) Intestinal calcium absorption: mechanisms and applications. Nutr J 117, 1347-1352.

Bronner F (1992) Current concepts of calcium absorption: an overview. Nutr J 122, 641-643.

Burton A (2001) Vitamin D derivatives convert colon cancer cells. Lancet Oncol 2, 593.

Cantorna MT (2000) Vitamin D and autoimmunity: is vitamin D status an environmental factor affecting autoimmune disease prevalence? Proc Soc Exp Biol Med 223, 230-233.

Chapuy MC, Perziosi P, Maamer M, Arnaud S, Galan P, Hercberg S \& Meunier PJ (1997) Prevalence of vitamin D insufficiency in an adult normal population. Osteoporos Int 7, 439-443.

Cheetham CH (1999) Time for a tablet containing high doses of vitamin D alone. Br Med J 318, 1284.

Compston JE (1998) Vitamin D deficiency: time for action. Br Med J 317, $1466-1467$.

Dawson-Hughes B, Harris SS, Krall EA, Dallal GE, Falconer G \& Green CL (1995) Rates of bone loss in postmenopausal women randomly assigned to one of two dosages of vitamin D. Am J Clin Nutr 61, 1140-1145.

Diamond T, Levy S, Smith A \& Day P (2000) Vitamin D deficiency is common in Muslim women living in a Sydney urban community. Bone 27S, 1S-54S.

Erben RG, Bromm S \& Stangassinger M (1998) Therapeutic efficacy of $1 \alpha, 25$-dihydroxyvitamin $\mathrm{D}_{3}$ and calcium in osteopenic ovariectomized rats: evidence for a direct anabolic effect of 1 $\alpha, 25$-dihydroxyvitamin $\mathrm{D}_{3}$ on bone. Endocrinology 139, 4319-4328.

Erben RG, Mosekilde L, Thomsen JS, Weber K, Leyshon A, Smith SY \& Phipps R (2002) Prevention of bone loss in ovariectomized rats by combined treatment with risedronate and $1 \alpha, 25$-dihydroxyvitamin $\mathrm{D}_{3}$. J Bone Miner Res 17, 1498-1511.

Erben RG, Scutt AM, Miao DS, Kollenkirchen U \& Haberey M (1997) Short-term treatment of rats with high dose 1,25-dihydroxyvitamin $\mathrm{D}_{3}$ stimulates bone formation and increases the number of osteoblast precursor cells in bone marrow. Endocrinology 138, 4629-4635.

Grant WB (2002) An ecologic study of dietary and solar ultraviolet-B links to breast carcinoma mortality rates. Cancer $\mathbf{9 4}, 272-281$.

Gueguen L \& Pointillart A (2000) The bioavailability of dietary calcium. $J$ Am Coll Nutr 19, 119S-136S.

Hanly JG, McKenna MJ, Quigley C, Freaney R, Muldowney FP \& FitzGerald MX (1985) Hypovitaminosis D and response to supplementation in older patients with cystic fibrosis. QJM 56, 377-385.

Hansen CM, Binderup L \& Hamberg KJ (2001) Vitamin D and cancer: effects of $1,25(\mathrm{OH}) 2 \mathrm{D} 3$ and its analogs on growth control and tumorigenesis. Front Biosci 6, D820-D848.

Heaney RP (2000) Vitamin D: how much do we need, and how much is too much? Osteoporos Int 11, 553-555.

Heldenberg D, Gershon T \& Weisman Y (1992) Effect of iron on serum 25-hydroxyvitamin D and 24,25-dihydroxyvitamin D concentrations. Am J Clin Nutr 56, 533-536.

Holick MF (2001) Meeting the vitamin D needs of the elderly. Nutr MD 27, 1-4.

Holick MF (2004) Vitamin D importance in the prevention of cancers, type 1 diabetes, heart disease, and osteoporosis. Am J Clin Nutr 79, $362-371$ 
Holick MF, Krane SM \& Potts JT (1986) Calcium, phosphorus and bone metabolism: calcium regulating hormones. In Harrison's Principles of Internal Medicine, 11th ed., pp. 1857-1870 [E Braunwald, TL Isselbacher, RG Petersdorf, JD Wilson, JB Martin and AS Fauci, editors]. New York: McGraw-Hill.

Hypponen E, Laara E, Reunanen A, Jarvelin MR \& Virtanen SM (2001) Intake of vitamin $\mathrm{D}$ and risk of type 1 diabetes: a birth-cohort study. Lancet, 358, (9292), 1476-1478.

Jasinghe VJ \& Perera CO (2005) Distribution of ergosterol in different tissues of mushrooms and its effect on the conversion of ergosterol to vitamin $\mathrm{D}_{2}$ by UV irradiation. Food Chem, 2, 541-546.

Kaastad TS, Reikeras O, Halvorsen V, Falch JA, Obrant KJ \& Nordsletten L (2001) Vitamin D deficiency and ovariectomy reduced the strength of the femoral neck in rats. Calcif Tissue Int 69, 102-108.

Liang CT, Barnes J, Takamato S \& Sacktor B (1989) Effect of age on calcium uptake in isolated duodenum cells: role of 1,25-dihydroxyvitamin $\mathrm{D}_{3}$. Endocrinology 124, 2830-2836.

Lips P \& Obrant KJ (1991) The pathogenesis and treatment of hip fractures. Osteoporos Int 1, 218-231.

McAlindon TE \& Felson DT (1996) Relation of dietary intake and serum levels of vitamin D to progression of osteoarthritis of the knee among participants in the Framingham Study. Ann Intern Med 125, 353-359.

McKenna MJ \& Freaney R (1998) Secondary hyperparathyroidism in the elderly: means to defining hypovitaminosis D. Osteoporos Int $\mathbf{8}$, S3-S6.

McKenna MJ, Freaney R, Byrne P, McBrinn Y, Murray B, Kelly M, Donne B \& O'Brien M (1995) Safety and efficacy of increasing wintertime vitamin D and calcium intake by milk fortification. QJM 88, 895-898.

McKenna MJ, Freaney R, Meade A \& Muldowney FP (1985) Prevention of hypovitaminosis D in the elderly. Calcif Tissue Int 37, 112-116.

Mancini D, Aaronson K, Foray A, Addresso V, Katz S \& Elizabeth S (1996) Vitamin D deficiency is common in heart failure. J Am Coll Cardiol 27, 338.

Mattila PH, Lampi AM, Ronkainen R, Toivo J \& Piironen V (2002) Sterol and vitamin $\mathrm{D}_{2}$ contents in some wild and cultivated mushrooms. Food Chem 76, 293-298.

Mau JL, Chen PR \& Yang JH (1998) Ultraviolet irradiation increased vitamin $\mathrm{D}_{2}$ content in edible mushrooms. J Agric Food Chem 46 5269-5272.

Mehta RG \& Mehta RR (2002) Vitamin D and cancer. J Nutr Biochem 13, 252-264.

Mellanby E (1919) An experimental investigation on rickets. Lancet I4985, 407-412.

Nagy TR, Charles W \& Jing LI (2001) Validation of peripheral dual-energy $\mathrm{X}$-ray absorptiometry for the measurement of bone mineral in intact and excised long bones of rats. J Bone Miner Res 16, 1682-1687.

Norman P, Moss I, Minder S, Gosling M \& Powell J (2002) Maternal and postnatal vitamin $\mathrm{D}$ ingestion influences rat aortic structure, function and elastin content. Cardiovasc Res 55, 369-374.

Outila TA, Mattila PH, Piironen VI \& Allardt CJEL (1999) Bioavailability of vitamin D from wild edible mushrooms (Cantharellus tubaeformis) as measured with a human bioassay. Am J Clin Nutr 69, 95-98.

Parfitt AM, Gallagher JC, Heaney RP, Johnston CC, Neer R \& Whedon CG (1982) Vitamin D and bone health in the elderly. Am J Clin Nutr 36, 1014-1031

Peleg S (1997) Molecular basis for differential action of vitamin D analogs. In Vitamin D, pp. 1011-1025 [D Feldman, FH Glorieux and JW Pike, editors]. New York: Academic Press.
Perera CO, Jasinghe VJ, Ng FL \& Mujumdar AS (2003) The effect of moisture content on the conversion of ergosterol to vitamin D in shiitake mushrooms. Drying Technol 21, 1093-1101.

Platz EA, Hankinson SE \& Hollis BW (2000) Plasma 1,25-dihydroxy- and 25-hydroxyvitamin D and adenomatous polyps of the distal colorectum. Cancer Epidemiol Biomarkers Prev 9, 1059-1065.

Polek TC \& Weigel NL (2002) Vitamin D and prostate cancer. J Androl 23, 9-17.

Ravinder G, Gupta N, Goswami D, Marwaha RK, Nikhil T \& Kochupillei N (2000) Prevalence and significance of low 25-hydroxyvitamin D concentrations in healthy subjects in Delhi. Am J Clin Nutr 72, 472-475.

Sadava D, Reme T \& Petersen K (1996) Hyperplasia, hyperproliferation and decreased migration rate of colonic epithelial cells in mice fed a diet deficient in vitamin D. Biol Cell 87, 113-116.

Schapira D, Linn S, Sarid M, Mokadi S, Kabala A \& Silbermann M (1995) Calcium and vitamin D enriched diets increase and preserve vertebral mineral content in aging laboratory rats. Bone 16, 575-582.

Schulz SR \& Morris HA (1999) Ionized calcium and bone turnover in the estrogen-deficient rat. Calcif Tissue Int $\mathbf{6 5}, 78-82$.

Schumann K, Classen HG, Hages M, Langenhol RP, Pietrzik K \& Biesalski HK (1997) Bioavailability of oral vitamins, minerals and trace elements in perspective. Arzneimittelforschung 47, 369-380.

Semba DR, Elizabeth G, Johnson BA, Guralnik JM \& Linda PF (2000) Vitamin D deficiency among older women with and without disability. Am J Clin Nutr 72, 1529-1534.

Speer G, Cseh K \& Winkler G (2001) Vitamin D and estrogen receptor gene polymorphisms in type 2 diabetes mellitus and in android type obesity. Eur J Endocrinol 144, 385-389.

Suda T, Deluca HF, Schnoes H \& Blunt JW (1969) 25-Hydroxyergocalciferol: a biologically active metabolite of vitamin $\mathrm{D}_{2}$. Arch Biochem Biophys 35, 182.

Takamoto S, Seino Y, Sacktor B \& Liang CT (1990) Effect of age on duodenal 1,25-dihydroxyvitamin D-3 receptors in Wistar rats. Biochim Biophys Acta 1034, 22-28.

Van-den-Berg H (1997) Bioavailability of vitamin D. Eur J Clin Nutr 51S, 76-79.

Vieth R (1999) Vitamin D supplementation, 25-hydroxyvitamin D concentrations, and safety. Am J Clin Nutr 69, 842-856.

Vieth R (2000) Problems with direct 25-hydroxyvitamin D assays, and the target amount of vitamin D nutrition desirable for patients with osteoporosis. Osteoporos Int 11, 635-636.

Vieth R, Cole DE, Hawker GA, Trang HM \& Rubin LA (2001) Wintertime vitamin D insufficiency is common in young Canadian women, and their vitamin D intakes do not prevent it. Eur J Clin Nutr 55, 1091-1097.

Vieth R \& Milojevic S (1995) Moderate vitamin $\mathrm{D}_{3}$ supplementation lowers serum 1,25-dihydroxy-vitamin $\mathrm{D}_{3}$ in rats. Nutr Res 15, $725-731$.

Williams FL \& Lloyd OL (1989) Latitude and heart disease [letter]. Lancet 333, 1072-1073.

Yan L, Prentice A, Zhang H, Wang X, String DM \& Glden MM (2000) Vitamin D status and parathyroid hormone concentrations in Chinese women and men from north-east of the People's Republic of China. Eur J Clin Nutr 54, 68-72.

Zittermann A, Schleithoff SS, Tenderich G, Berthold HK, Korfer R \& Stehle P (2003) Low vitamin D status: a contributing factor in the pathogenesis of congestive heart failure? J Am Coll Cardiol 41, $105-112$. 